\title{
Do we know enough about human immunodeficiency virus and COVID-19 coinfection?
}

The past several months have seen monumental changes throughout the world due to the coronavirus disease-2019 (COVID-19) pandemic. These changes range from economic hardships, atrophied social lives, and, in the worst case, the dangerous health risks of becoming infected. At this moment there are 20.1 million confirmed cases of COVID-19 and almost 737,000 deaths. ${ }^{[1-4]}$ While many studies are focusing on advising healthy people on the dangers of COVID infection, Shareef et al. ${ }^{[1-4]}$ have decided to base their study on at-risk patients, specifically those with human immunodeficiency virus (HIV) who have been coinfected with COVID-19. Although the most reliable testing method is the polymerase chain reaction (PCR)-based test, numerous additional testing methods have been developed, including antibody/serological technique. ${ }^{[5]}$

The current issue of Avicenna Journal of Medicine is a systematic review of SARS-CoV-2 and HIV coinfection, where the authors shed light on a neglected topic while offering advice on the actions that should be taken if an HIV infected individual becomes affected and acquired SARSCoV-2 (COVID-19) coinfection. ${ }^{[6]}$ By utilizing the metaanalysis methodology, they reviewed existing literature pertaining to COVID-19/HIV coinfection systematically, narrowing their search to seven reports, in which a total of 16 cases were reported. The methodology of each report was then assessed using a data quality gage developed by Murad et al. ${ }^{[6]}$ which gives a score out of 4 to a study (1-2 being a poor-quality study, 4 being a good-quality study). Of the cases that qualified for this report, three were given a score of 4,10 were given a score of 3 , and 3 were given scores of 1 or 2 .

The main variables extracted from each case included age and gender of the patient, duration of HIV infection, name of antiretroviral therapy (ART), presence of comorbidities, clinical presentation, duration of illness prior to presentation, presence of hypoxia on initial presentation, patient's most recent HIV RNA viral load and CD4+ count, initial laboratory workup and imaging findings, different treatment modalities that were provided, last follow-up day, patient's status, and disposition plan. Statistical analysis was then performed, calculating the mean and standard deviation of continuous variables, while categorical variables were depicted as percentages and numbers. ${ }^{[6]}$ These statistics were processed using IBM Statistical Package for the Social Sciences (SPSS).

The mean age of patients in this study was $42.7 \pm 12.8$ years and all were male except for one. The average length of infection with HIV for the patients was $10.2 \pm 5.2$ years. 13 out of 16 patients were taking ART at home with documented compliance and suppressed viral load. One patient was poorly compliant with ART due to bipolar disorder, and two others were not taking ART before presenting with COVID-19. Regarding comorbidities, four patients were hypertensive, two patients were diabetic, one was obese, one had syphilis, and one had a reported history of hepatitis C virus. ${ }^{[6]}$

The authors recorded $94 \%$ of patients presented with a fever, $88 \%$ had a dry cough, and $81 \%$ presented with dyspnea and the mean duration of illness after presentation was $10.17 \pm$ 5.19 days. Five patients also suffered from hypoxia and required oxygen via nasal cannula, two patients required manual ventilation; one improving and the other being placed on extracorporeal membrane oxygenation. The screening and laboratory findings of the patients infected with HIV and COVID-19 were found to be similar to those without HIV coinfection. Although the presence of HIV infection indicates a certain element of immunosuppression, there was a tremendous improvement in the effectiveness of drugs used to treat HIV-infected patients. Therefore, and rightfully so, the recommended approach to patients who have both HIV and COVID-19 coinfection should not stray from the current recommended guidelines for COVID-19 infection. ${ }^{[6]}$

Although the study sample is small, in our opinion, the authors gave healthcare stakeholders an adequate preliminary overview of this topic and its related clinical implications. They concluded by acknowledging the fact that the findings of their review are preliminary, and require further evidence. The implications of the paper are summarized by providing recommendations for the management of HIV/COVID-19 coinfection and are summarized as follows; follow guidelines of social distancing, self-isolation, personal hygiene, strict compliance with ART, and practicing healthy behaviors to control nonrelated chronic conditions. Furthermore, they pointed out at the end of their review that future 
research and analysis would be highly recommended and they went further by specifying some of these goals to strive for. Although there was a tremendous effort by all scientists all over the world to improve our understanding of this pandemic, there are obviously still many gaps in our knowledge. These include, but are not limited to, the role of lymphopenia in pathogenesis, testing patterns and results' consistency, clinical outcome, and effectiveness of HIV treatment in the event of HIV/COVID-19 coinfection.

The authors of this insightful paper should be commended for attempting to tackle such a new and poorly understood issue; however, some issues have to be reviewed to give readers better data and more up-to-date statistics. There are most probably more eligible studies to include in this paper, as the sample of size of just 16 patients is small and may lead to skewed statistics if an attempt to reference the paper is made in the future.

At the end of 2019, many people were looking forward to a fresh start and smooth transition into 2020. Unfortunately, the world was blindsided by the COVID-19 pandemic, and its consequences are still being felt at this moment, with no sign of stopping. Many questions arise whether the pandemic will finally slow or come to a stop with the approach of 2021 just around the corner, and all of us are hoping for a happy conclusion to $2020 .{ }^{[7,8]}$ These wishes include the successful development of an effective vaccine..$^{[9]}$

\section{Financial support and sponsorship}

Nil.

\section{Conflicts of interest}

There are no conflicts of interest.

Ali M. Alabbadi, Mousa A. Al-Abbadi

Department of Pathology, Microbiology and Forensic Medicine, University of Jordan School of Medicine, Amman, Jordan

Address for correspondence: Prof. Mousa A. Al-Abbadi, Department of Pathology, Microbiology and Forensic Medicine, The University of Jordan School of Medicine, Queen Rania Street, Jubaiha, Amman, Jordan. E-mail: alabbadima@yahoo.com

\section{References}

1. Pascarella G, Strumia A, Piliego C, Bruno F, Del Buono R, Costa F, et al. COVID-19 diagnosis and management: A comprehensive review.J Intern Med 2020;288:192-206.

2. Adhikari SP, Meng S, Wu YJ, Mao YP, Ye RX, Wang QZ, et al. Epidemiology, causes, clinical manifestation and diagnosis, prevention and control of coronavirus disease (COVID-19) during the early outbreak period: A scoping review. Infect Dis Poverty 2020;9:29.

3. Rothan HA, Byrareddy SN. The epidemiology and pathogenesis of coronavirus disease (COVID-19) outbreak. J Autoimmun 2020;109:102433.

4. Available from: https://www.who.int/emergencies/diseases/novelcoronavirus-2019.

5. Loeffelholz MJ, Tang YW. Laboratory diagnosis of emerging human coronavirus infections - the state of the art. Emerg Microbes Infect 2020;9:747-56.

6. Shareef MA, Bashaiwth HM, AlAkbari AO, Bahamran MS, AlAmodi MO, Albaiti $\mathrm{SH}$, et al. A systematic review of contemporary evidence on SARS-CoV-2 and HIV coinfection: What does it look like up to date?. Avicenna J Med 2020;10:189-97.

7. Alabbadi AM, Yassin DF, Mansour AT, Al-Abbadi MA. COVID-19 and peripheral smear chat. Acta Cytol 2020;Aug 14:1-3.

8. Yassin DF, Al-Abbadi MA. Cytology formation: "A neutrophilic happy new year". Acta Cytol 2018;62:1-2.

9. Wu SC. Progress and concept for COVID-19 vaccine development. Biotechnol J 2020;15:e2000147.

\begin{tabular}{|l|l|}
\hline \multicolumn{2}{|c|}{ Access this article online } \\
\hline Quick Response Code: & Website: www.avicennajmed.com \\
\cline { 2 - 2 } & \\
\hline
\end{tabular}

This is an open access journal, and articles are distributed under the terms of the Creative Commons Attribution-NonCommercial-ShareAlike 4.0 License, which allows others to remix, tweak, and build upon the work non-commercially, as long as appropriate credit is given and the new creations are licensed under the identical terms.

For reprints contact: reprints@ @medknow.com

Cite this article as: Alabbadi AM, Al-Abbadi MA. Do we know enough about human immunodeficiency virus and COVID-19 coinfection?. Avicenna J Med 2020;10:133-4. 